\title{
Morphometric Analysis and Classification of the Cross-Sectional Shape of the C2 Lamina
}

\author{
Soyeon Kim, Dai-Soon Kwak, and In-Beom Kim \\ Catholic Institute for Applied Anatomy, Department of Anatomy, College of Medicine, \\ The Catholic University of Korea, 222 Banpo-daero, Seocho-gu, Seoul 06591, Republic of Korea
}

Correspondence should be addressed to Dai-Soon Kwak; daisoon@catholic.ac.kr and In-Beom Kim; ibkimmd@catholic.ac.kr

Received 18 May 2017; Revised 12 July 2017; Accepted 21 August 2017; Published 25 September 2017

Academic Editor: Ayhan Cömert

Copyright (C) 2017 Soyeon Kim et al. This is an open access article distributed under the Creative Commons Attribution License, which permits unrestricted use, distribution, and reproduction in any medium, provided the original work is properly cited.

A thorough understanding of the morphology of the lamina of the second cervical vertebra (C2) is important for safe C2 translaminar screw placement. Although anatomical characteristics of the C2 lamina have been widely documented, individual differences in morphology have not been addressed. The aim of this study was to morphometrically analyze the cross-sectional shape of the C2 lamina and classify the shape to describe individual differences. Morphometric analysis was conducted on 145 three-dimensional C2 models based on computerized tomography images from Korean adult cadavers. Several parameters were measured on a cross-section image of the lamina model. Based on numerical criteria, all of the C2 lamina's cross-sectional shapes could be categorized into three distinctive morphological types: pyriform, ellipse, and obpyriform shapes. We confirmed that most Koreans can accommodate C2 translaminar screw placement with a lower limit of the 95\% confidence interval of thickness measured at $6.26 \mathrm{~mm}$. Morphometric analysis suggested that the obpyriform-shaped lamina (4.48\%) is likely to require screw trajectory adjustment to avoid cortical breakout of the screw. Our results will enhance current anatomical understanding of the $\mathrm{C} 2$ lamina and thus facilitate safer C2 translaminar screw placement.

\section{Introduction}

The axis is the second vertebra (C2) in the upper cervical spine that contributes to head and neck movement. The $\mathrm{C} 2$ has unique anatomical features, such as the dens (odontoid process) and superior articulating facets. The lamina of the $\mathrm{C} 2$ is reported to be the largest in the cervical spine and is often used during translaminar fixation to correct atlantoaxial or occipitocervical instability $[1,2]$. Screws are inserted into the laminas of the $\mathrm{C} 2$ bilaterally to fuse the level with the relevant upper or lower vertebrae $[2,3]$. Other options for cervical instrumentation include transarticular screw placement and C2 pars/pedicle screw fixation. Despite their biomechanical competitiveness, these fixation techniques entail a high risk of vertebral artery injury due to their close proximity to the screw path [4-7]. In 2004, Wright [2] proposed translaminar screw fixation as an alternative technique for posterior atlantoaxial arthrodesis because of relatively good visibility of relevant structures during the procedure.
Since the introduction of the translaminar screw technique by Wright, a number of studies have assessed the morphology of the C2 lamina across various populations [818]. Laminas are generally described as flat, bilateral plates. However, Wang [9] noted large morphological differences in C2 lamina among individuals. Conducting the translaminar screw fixation technique without consideration of individual structural differences can result in screw breakout into the dorsal or ventral space, which can increase the risk of postoperative cervical instability or neurological complications [19-21]. It is, therefore, expected that a study of the three-dimensional (3D) structure of the C2 lamina would enhance the current anatomical understanding, thus facilitating safer $\mathrm{C} 2$ translaminar screw placement. The 3D structure of the lamina can be delineated with a section image that is perpendicular to the longitudinal axis of the lamina. Therefore, we examined the morphological characteristics of the $\mathrm{C} 2$ lamina by analyzing the cross-sectional shape of 3D lamina models generated from computerized tomography (CT) 

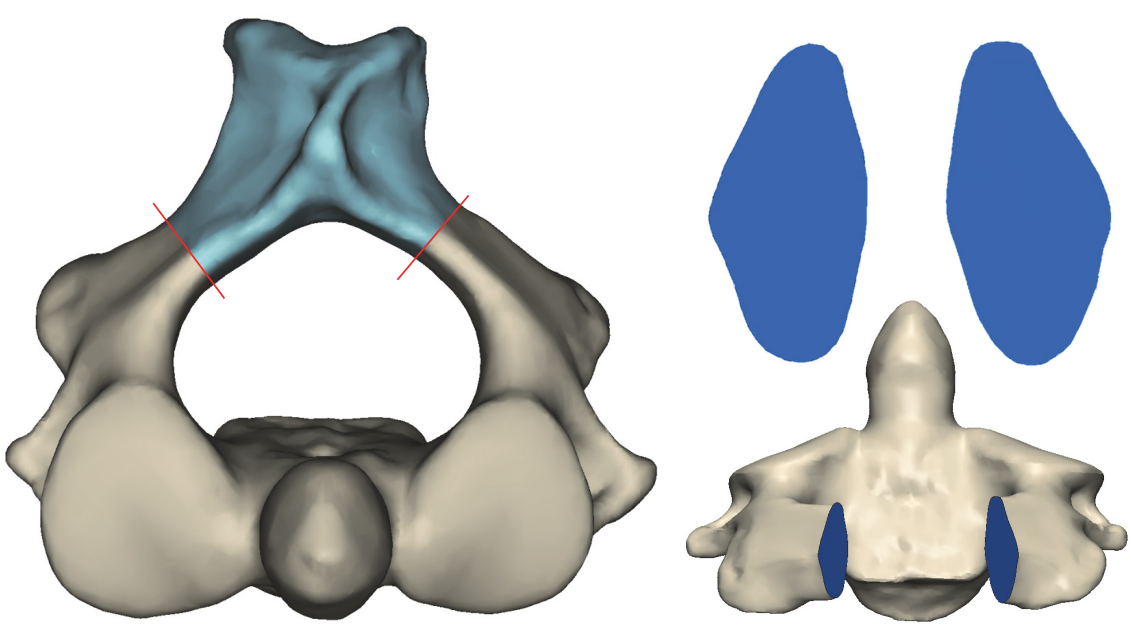

Figure 1: Acquisition of section shapes of the lamina on a 3D model of the C2.

images. Four anatomical parameters related to the section shape of the C2 lamina were investigated, and the section shapes were categorized so that the varied section shapes among individuals can be best explained in relation to the safe screw placement.

\section{Materials and Methods}

CT images of the cervical vertebrae of Korean cadavers were randomly selected from the database of the Catholic Digital Human Library. The Catholic Digital Human Library stores scanned CT images of cadavers that were donated to the Catholic University of Korea. Each image contained demographic information such as age and gender; however, personal information that can be linked to specific individuals was unavailable $[22,23]$. CT images had $0.6 \mathrm{~mm}$ or $0.8 \mathrm{~mm}$ slice thickness and $0.391 \mathrm{~mm}$ to $0.461 \mathrm{~mm}$ pixel dimensions (SOMATOM Definition AS +, Siemens Healthcare, Germany). CT scans were performed with a plastic ball of known size (diameter: 2.25 inches) positioned alongside the cadavers for size calibration in order to ensure that the reconstructed $3 \mathrm{D}$ models represented the size of the real bone [23-25]. One hundred forty-five CT scans of the $\mathrm{C} 2$ were retrieved that had intact lamina with no signs of surgical instrumentation and no deformities on the bone. Sixty-five specimens were from females with an average age of 49 (21-96) years, and eighty specimens were from males with an average age of 54.5 (20-95) years.

A 3D modeling software (Mimics Ver. 19, Materialise, Belgium) enabled reconstruction of 3D models of the axis and extraction of bilateral section shapes of the lamina. The 3D models of the lamina were cut perpendicular to the longitudinal axis of the lamina at the narrowest portion on the axial view, as this portion dictates safe translaminar screw placement (Figure 1). Two observers separately adjusted the anatomical alignment of the 3D models of the $\mathrm{C} 2$ on Mimics software and made an orthogonal cut on the axial view. One

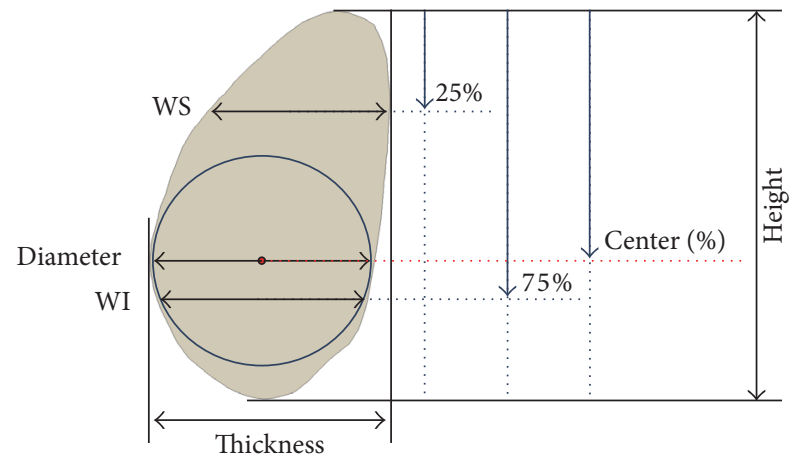

FIgURE 2: Measurement parameters, WS: width at 25\% of the height from the top of the lamina; WI: width at $75 \%$ of the height from the top of the lamina.

observer repeated the alignment and cutting process to ensure intraobserver reliability. A scientific programming language (MatLab, R2016, MathWorks, MA) automatically measured variables, including thickness, height, diameter, the center position of a maximally applicable circle, and width at $25 \%$ (WS) and $75 \%$ (WI) of height from the top of the lamina, on the extracted section shape of the lamina (Figure 2). MatLab was programmed to automatically draw a maximally applicable circle that did not break out of the outline of the laminar section on the sectional image. Therefore, the diameter and the center position were expected to more precisely describe the width and position of the safest part of the lamina for the screw to pass through without penetrating cortical bone. All measurement parameters were automatically calculated with certain landmark points on the section images, and two observers assessed correct alignment and landmark points created through the program.

The ratio of WS to WI (WS/WI) and the center position values were used to analyze the cross-sectional shape of the $\mathrm{C} 2$ in relation to the part of the lamina within which a 
TABLE 1: Morphometric parameters of the C2 lamina in the study population.

\begin{tabular}{|c|c|c|c|c|}
\hline Parameters & $\begin{array}{c}\text { Female } \\
(N=130)\end{array}$ & $\begin{array}{c}\text { Male } \\
(N=160)\end{array}$ & $\begin{array}{l}\text { Combined } \\
(N=290)\end{array}$ & $p$ \\
\hline Thickness (mm) & $6.4 \pm 1.3$ & $7.1 \pm 1.1$ & $6.82 \pm 1.2$ & $<0.001$ \\
\hline Diameter (mm) & $6.0 \pm 1.3$ & $6.7 \pm 1.1$ & $6.39 \pm 1.2$ & $<0.001$ \\
\hline Height (mm) & $12.7 \pm 1.4$ & $14.1 \pm 1.3$ & $13.5 \pm 1.5$ & $<0.001$ \\
\hline Center (\%) & $56.9 \pm 7.2$ & $57.7 \pm 8.0$ & $57.3 \pm 7.7$ & 0.356 \\
\hline
\end{tabular}

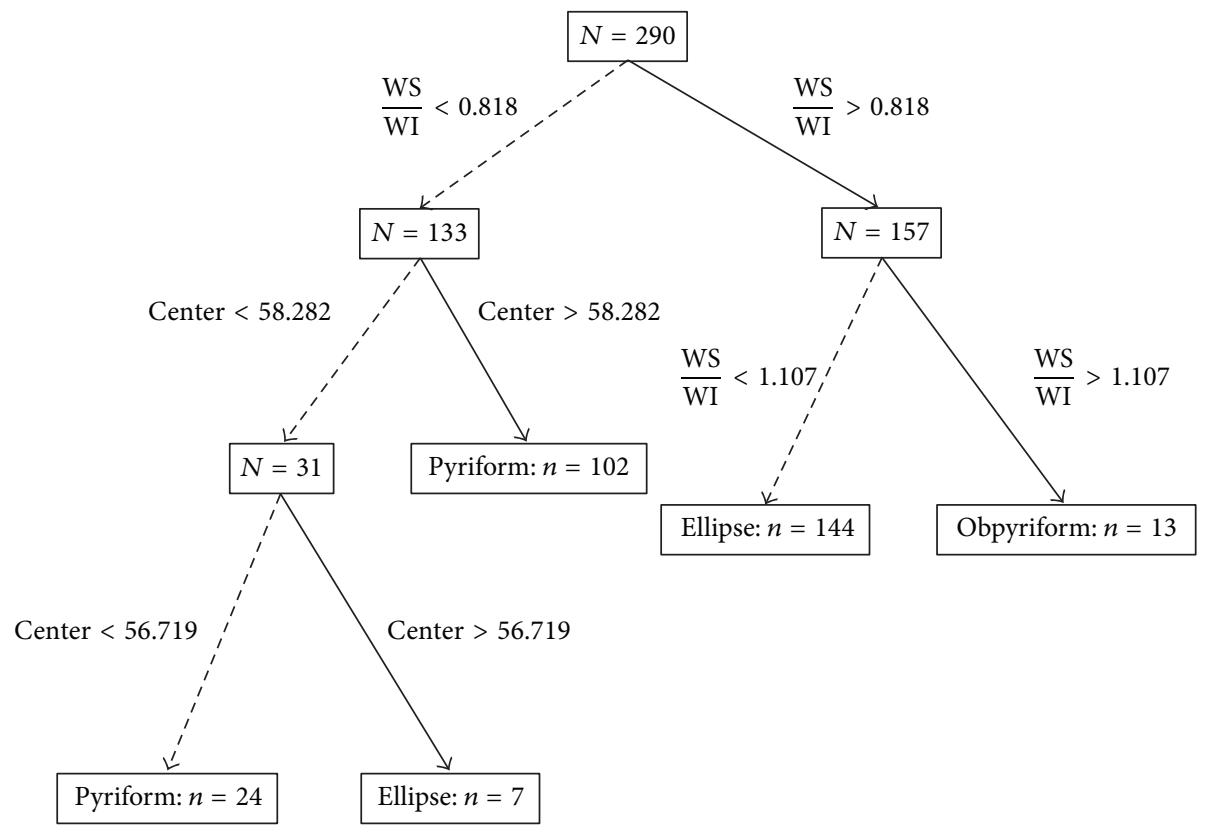

Figure 3: Classification tree for determination of section shape type, WS: width at $25 \%$ of the height from the top of the lamina; WI: width at $75 \%$ of the height from the top of the lamina.

screw with the maximum diameter could be safely located. A classification tree was created using the Classification Tree Package via R (Ver. 1.0.44, RStudio, Inc.) to determine cutoff values, thus excluding subjectivity (Figure 3 ). Average differences were compared with Student's $t$-test and ANOVA.

\section{Results}

The laminar section had thickness of $6.82 \pm 1.25 \mathrm{~mm}$ and height of $13.46 \pm 1.5 \mathrm{~mm}$ (Table 1). The diameter of the maximally applicable circle was $6.40 \pm 1.21 \mathrm{~mm}$. A significant difference was noted between the values of WS and WI $(p<0.001)$; the WS was $4.69 \pm 1.15 \mathrm{~mm}$ and the WI was $5.73 \pm 1.19 \mathrm{~mm}$. On average, the center of the maximally applicable circle was positioned at $57.31 \%$ of the lamina's height from the top. Differences between the sexes were found in the three parameters of thickness, height, and diameter, with larger dimensions in males $(p<0.001)$. For the four measurement variables thickness, height, diameter, and center position, intraclass correlation coefficients (ICCs) revealed excellent interobserver reliability (ICCs $=0.943 \sim 0.989)$ and intraobserver reliability $(\mathrm{ICC} s=0.936 \sim 0.990)$.
The classified cross-sectional shapes in relation to the location of the screw with the maximum diameter were named as obpyriform, pyriform, and ellipse according to the characteristics of each segregated group (Figure 4). A group of section shapes widest at the top was named obpyriform, and two other groups of section shapes widest at the middle and bottom were designated as ellipse and pyriform, respectively. The classification tree enabled numerical determination of section shapes of the C2 lamina (Figure 3). If the ratio of WS to WI (WS/WI) was greater than $1.107 \mathrm{~mm}$, the section shape was categorized as obpyriform. If WS/WI was within the range of $0.818 \mathrm{~mm}$ and $1.107 \mathrm{~mm}$, the section shape was categorized as ellipse. On the basis of these criteria, $133 \mathrm{sec}-$ tion shapes with WS/WI less than $0.818 \mathrm{~mm}$ remained unclassified, so the center position value was further selected to analyze section shape. In the group of 133 unclassified section shapes, if the center value was within the range of $56.72 \%$ and $58.28 \%$, the section shape was classified as elliptical. The rest of the 124 section shapes were classified as pyriform.

The elliptical section shape was the most common shape, accounting for $52.07 \%$ (151 of 290 laminas) of the specimens, followed by the pyriform section shape (43.45\%, 126 of 290 laminas). Thirteen of 290 laminar section shapes $(4.48 \%)$ 


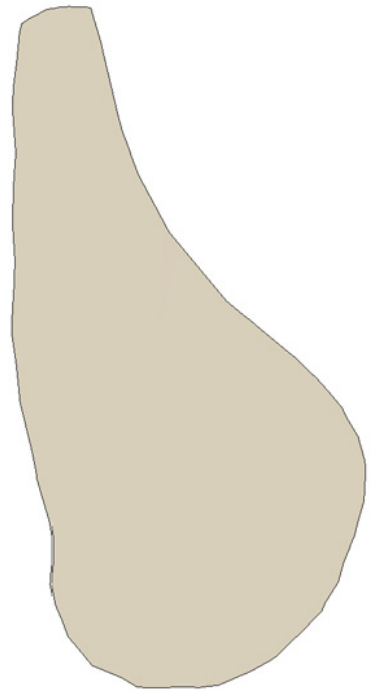

(a)

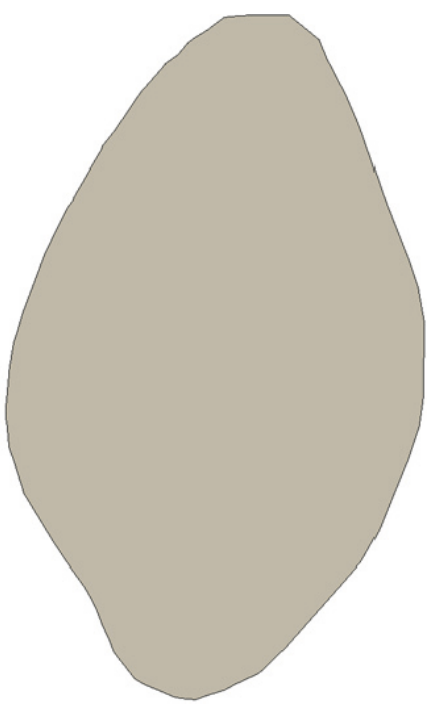

(b)

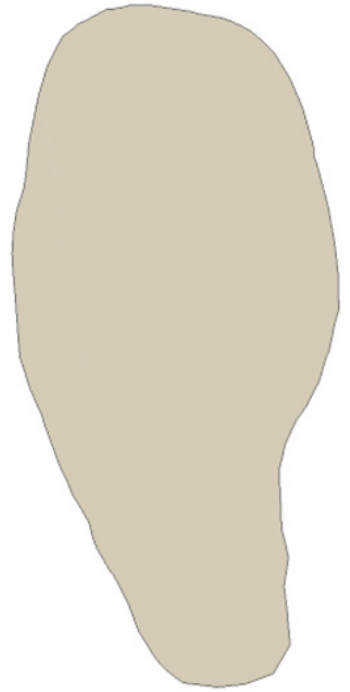

(c)

FIGURE 4: Types of cross-section shapes of the lamina: (a) pyriform shape (43.45\%); (b) elliptical shape (52.07\%); (c) obpyriform shape (4.48\%).

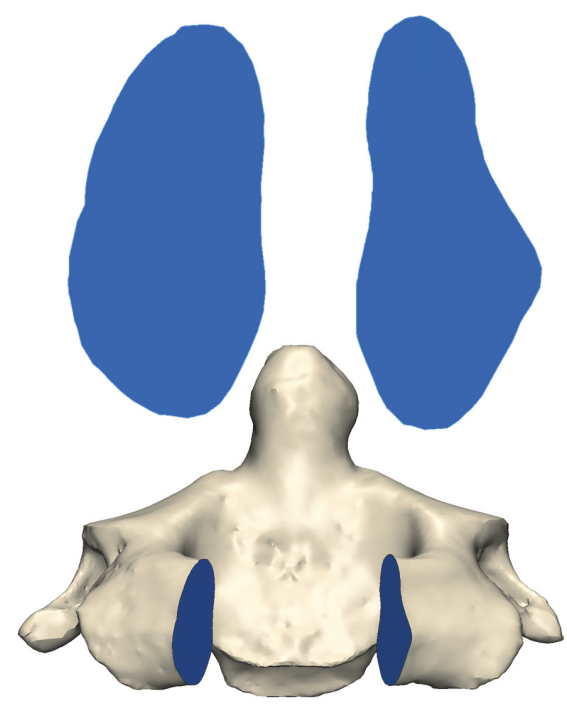

(a)

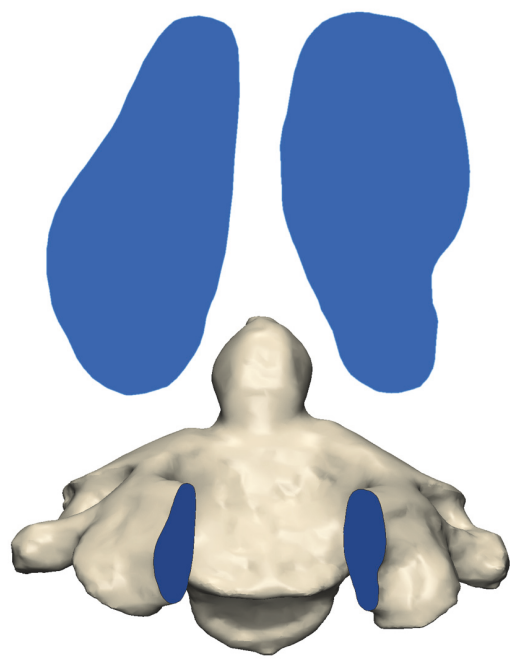

(b)

Figure 5: Asymmetric laminas (54 of 145 axes): (a) ellipse (L) and pyriform (R) (45 of 145 axes); (b) pyriform (L) and obpyriform (R) (9 of 145 axes).

had an obpyriform shape. The center position values varied according to the type of cross-section shape $(p<0.001)$.

Asymmetric laminas were found, in which the bilateral laminas were of different section shapes. Fifty-four of 145 axes showed this asymmetric pattern; of these 54 axes, 9 had an obpyriform section shape on either the left or right side (Figure 5).

\section{Discussion}

Since the introduction of translaminar screw fixation by Wright in 2004 [2], the morphometric characteristics of the
C2 lamina have been widely studied to determine the suitability of the technique across different populations [8-11, 18, 26]. In particular, the measurement of thickness has been emphasized because it affects the maximum translaminar screw size. Small differences in thickness were noted among studies with values ranging from $5.17 \pm 1.42 \mathrm{~mm}$ to $6.7 \pm$ $1.5 \mathrm{~mm}[8-10,12-18]$. In the cadaveric study of Cassinelli et al. [8], the thickness of the lamina of 420 axis was $5.77 \pm$ $1.31 \mathrm{~mm}$. Similar studies conducted in the United States have identified laminar thicknesses of $6.3 \pm 1.3 \mathrm{~mm}$ [9] and $5.5 \pm$ $1.4 \mathrm{~mm}$ [18]. Kim et al. [10] found that laminar thickness in a sample of Korean patients was $5.66 \pm 1.02 \mathrm{~mm}$. In Chinese 
TABLE 2: Comparison of morphometric parameters of the C2 lamina across studies.

\begin{tabular}{|c|c|c|c|c|c|}
\hline & Population & $\begin{array}{c}\text { Specimens } \\
\text { (number of axes) }\end{array}$ & $\begin{array}{l}\text { Thickness } \\
(\mathrm{mm})\end{array}$ & $\begin{array}{c}\text { Thickness } \\
>5.5 \mathrm{~mm} \\
(\%)\end{array}$ & $\begin{array}{c}95 \% \mathrm{CI} \\
\text { (lower-upper) }\end{array}$ \\
\hline Current study & Korean & $\begin{array}{c}145 \\
\text { (CT scans) }\end{array}$ & $6.39 \pm 1.21$ & 75.9 & $6.26-6.54$ \\
\hline Cassinelli et al. (2006) & American & 420 & $5.77 \pm 1.31$ & $\begin{array}{c}70.5 \\
(>5 \mathrm{~mm}) \\
\end{array}$ & Null \\
\hline Wang (2006) & American & $\begin{array}{c}38 \\
\text { (Cadavers) }\end{array}$ & $6.30 \pm 1.30$ & 79 & Null \\
\hline Kim et al. (2008) & Korean & $\begin{array}{c}102 \\
\text { (CT scans) }\end{array}$ & $5.66 \pm 1.02$ & 61.3 & Null \\
\hline Ma et al. (2010) & Chinese & $\begin{array}{c}120 \\
\text { (Cadavers) }\end{array}$ & $5.87 \pm 1.29$ & $\begin{array}{c}83.3 \\
(\geq 4 \mathrm{~mm}) \\
\end{array}$ & Null \\
\hline Bhatnagar et al. (2010) & American & 50 & $5.50 \pm 1.40$ & 94 & Null \\
\hline Hu et al. (2010) & Chinese (Han) & 28 & $6.70 \pm 1.50$ & "Bulk" & Null \\
\hline Xin-Yu et al. (2011) & Chinese & $\begin{array}{c}96 \\
\text { (Cadavers) } \\
112 \\
\text { (CT scans) } \\
\end{array}$ & $\begin{array}{l}6.20 \pm 5.20 \\
6.60 \pm 1.50\end{array}$ & $\begin{array}{c}85 \\
(>5 \mathrm{~mm})\end{array}$ & Null \\
\hline Yusof and Shamsi (2012) & Malaysian & $\begin{array}{c}98 \\
\text { (CT scans) }\end{array}$ & $5.60 \pm 1.20$ & $\begin{array}{c}75.5 \\
(\geq 5 \mathrm{~mm})\end{array}$ & Null \\
\hline Sharma et al. (2015) & Indian & $\begin{array}{c}38 \\
\text { (Cadavers) } \\
\text { (CT scans) }\end{array}$ & $\begin{array}{l}5.17 \pm 1.42 \\
5.57 \pm 1.28\end{array}$ & $\begin{array}{l}36.9 \\
\text { NA }\end{array}$ & Null \\
\hline $\begin{array}{l}\text { Saetia and Phankhongsab } \\
\text { (2015) }\end{array}$ & Thai & 200 & $6.64 \pm 1.36$ & 79 & Null \\
\hline
\end{tabular}

populations, the thickness of the lamina ranged from $5.87 \pm$ $1.29 \mathrm{~mm}$ to $6.70 \pm 1.50 \mathrm{~mm}$ [12-14]. The thickness values in Indian [16] and Malaysian [15] populations were measured relatively small as $5.17 \pm 1.42 \mathrm{~mm}$ and $5.60 \pm 1.20 \mathrm{~mm}$, respectively. Saetia and Phankhongsab [17], on the other hand, reported the thickness as $6.64 \pm 1.36 \mathrm{~mm}$ in a Thai population. These differences in thickness can be explained by different methodologies, including materials, specimens, measurement methods, or the definition of thickness.

Despite these differences, many researchers have concluded that most laminas can tolerate the placement of a $3.5 \mathrm{~mm}$ translaminar screw, assuming a tolerance margin of $1 \mathrm{~mm}[9-11,14,21]$ (Table 2). The current study also found that most specimens could safely accommodate a $3.5 \mathrm{~mm}$ translaminar screw. The lower and upper limits of the $95 \%$ confidence interval of laminar thickness were $6.26 \mathrm{~mm}$ and $6.54 \mathrm{~mm}$, respectively, and $75.9 \%$ of laminas had thickness greater than $5.5 \mathrm{~mm}$.

These linear measurements, however, only provide partial information on the lamina's $3 \mathrm{D}$ structure in the general population and fail to capture individual morphological differences. These thickness measurements cannot indicate the location of the thickest portion on the cross-section surface of the lamina. Ma et al. [13] and Sharma et al. [16] reported that the lamina is widest at the middle one-third. These results assume that the general shape of the laminar section is an ovoid. However, Senoglu et al. [11] showed that the lower one-third of the C2 lamina had the widest width, followed by the middle one-third and the upper one-third. In a morphometric study that assessed the cross-sectional area of the lamina [9], morphological diversity in cross-section shape was noted, although a detailed description was not provided. It can be assumed that, within the general population, thickness varies within individual lamina; for example, the lamina can have a much wider inferior than superior part and vice versa. However, there is limited data available regarding individual structural differences in the shape of the lamina.

The current guidelines for screw placement advise that the screw trajectory be directed toward the caudal portion of the lamina or parallel to the downslope of the lamina in order to avoid ventral breakout $[2,8,14,26]$. Yue et al. [27] and $\mathrm{Hu}$ et al. [14] recommended the entry point of the screws be $5 \mathrm{~mm}$ posterior to the post-edge of the spinal canal. In terms of the screw angle, several studies measured the angles of the screw trajectory against the axis of the spinous process $[8,10$, $12,16,26,27]$. The suggested screw angles, however, were varied between studies ranging from $42.45^{\circ}$ to $59.19^{\circ}$ and limited to the angles measured in the axial plane. Although a couple of researchers suggested angles measured in both axial and coronal planes $[13,14]$, these guidelines may not benefit those individuals having atypical C2 lamina structure and thus may increase the risk of cortical breach and potentially compromise biomechanical rigidity. Therefore, we analyzed the 
cross-sectional shape of the C2 lamina to confirm its structural diversity.

In the current study, $4.48 \%$ of the specimens (13 of 290 laminas) showed an obpyriform section shape, which previously has not been described in the literature. Of these 13 obpyriform-shaped laminas, five had thickness less than $5.5 \mathrm{~mm}$, and the rest required translaminar screws to be placed in the cephalad half of the lamina in order to avoid cortical breach, which is inconsistent with the established advice. This finding demonstrates the importance of thorough preoperative planning using CT images, with additional consideration of the laminar section shape. In addition, although laminar asymmetry in relation to sectional surface was found in $37.24 \%$ of the studied specimens, none of the four morphometric measurements showed significant differences between sides. This discrepancy indicates that the asymmetric lamina is unlikely to be distinguished with a single measurement variable, but rather with the sectional shape criteria based on several measurement variables. Additional information on asymmetric section shapes could facilitate more efficient use of feasible laminas for translaminar screw placement, assisting surgeons in deciding which side should receive the screw superiorly.

\section{Conclusion}

This study provided morphometric data and analyzed structural variation in the C2 lamina in a Korean population, demonstrating the feasibility of translaminar screw fixation. The morphological analysis confirmed a distinctive "obpyriform" type of C2 laminar section shape in $4.48 \%$ of the studied specimens. Other common laminar section shapes were classified into pyriform and elliptical section shapes. Asymmetric laminas were noted in $37.24 \%$ of the studied C2 samples, which surgeons should consider when deciding screw placement order. The results of the current study are expected to enhance the current anatomical understanding of the C2 lamina in three dimensions. Additional consideration of the lamina's 3D structure during preoperative planning will enhance patient safety and the outcomes of translaminar screw fixation.

\section{Conflicts of Interest}

The authors declare that they have no conflicts of interest regarding this paper.

\section{References}

[1] R. Xu, A. Burgar, N. A. Ebraheim, and R. A. Yeasting, "The quantitative anatomy of the laminas of the spine," Spine, vol. 24, no. 2, pp. 107-113, 1999.

[2] N. M. Wright, "Posterior C2 fixation using bilateral, crossing C2 laminar screws: case series and technical note," Journal of Spinal Disorders and Techniques, vol. 17, no. 2, pp. 158-162, 2004.

[3] T. Matsubara, J. Mizutani, M. Fukuoka, T. Hatoh, H. Kojima, and T. Otsuka, "Safe atlantoaxial fixation using a laminar screw (intralaminar screw) in a patient with unilateral occlusion of vertebral artery: Case report," Spine, vol. 32, no. 1, pp. E30-E33, 2007.

[4] J. S. Yeom, J. M. Buchowski, H.-J. Kim, B.-S. Chang, C.-K. Lee, and K. D. Riew, "Risk of vertebral artery injury: Comparison between C1-C2 transarticular and C2 pedicle screws," Spine Journal, vol. 13, no. 7, pp. 775-785, 2013.

[5] S. W. Lau, L. Kit Sun, R. Lai et al., "Study of the anatomical variations of vertebral artery in C2 vertebra with magnetic resonance imaging and its application in the c1-c2 transarticular screw fixation," Spine, vol. 35, no. 11, pp. 1136-1143, 2010.

[6] M. Neo, S. Fujibayashi, M. Miyata, M. Takemoto, and T. Nakamura, "Vertebral artery injury during cervical spine surgery: a survey of more than 5600 operations," Spine, vol. 33, no. 7, pp. 779-785, 2008.

[7] W. M. Gluf, M. H. Schmidt, and R. I. Apfelbaum, "Atlantoaxial transarticular screw fixation: a review of surgical indications, fusion rate, complications, and lessons learned in 191 adult patients," Journal of Neurosurgery Spine, vol. 2, no. 2, pp. 155163, 2005.

[8] E. H. Cassinelli, M. Lee, A. Skalak, N. U. Ahn, and N. M. Wright, "Anatomic considerations for the placement of C2 laminar screws," Spine, vol. 31, no. 24, pp. 2767-2771, 2006.

[9] M. Y. Wang, "C2 crossing laminar screws: Cadaveric morphometric analysis," Neurosurgery, vol. 59, no. 1, pp. S-84-S-88, 2006.

[10] Y.-J. Kim, W. T. Rhee, S.-B. Lee, S.-H. You, and S.-Y. Lee, "Computerized tomographic measurements of morphometric parameters of the $\mathrm{C} 2$ for the feasibility of laminar screw fixation in Korean population," Journal of Korean Neurosurgical Society, vol. 44, no. 1, pp. 15-18, 2008.

[11] M. Senoglu, D. Ozbag, and Y. Gumusalan, "intralaminar screw placement: a quantitative anatomical and morphometric evaluation," Turkish Neurosurgery, vol. 19, no. 3, pp. 245-248, 2009.

[12] L. Xin-Yu, Z. Kai, G. Laing-Tai, Z. Yan-Ping, and L. Jian-Min, "The anatomic and radiographic measurement of C2 lamina in Chinese population," European Spine Journal, vol. 20, no. 12, pp. 2261-2266, 2011.

[13] X.-Y. Ma, Q.-S. Yin, Z.-H. Wu, H. Xia, K. Daniel Riew, and J.-F. Liu, "C2 Anatomy and dimensions relative to translaminar screw placement in an Asian population," Spine, vol. 35, no. 6, pp. 704-708, 2010.

[14] Y. Hu, X. F. He, Y. J. Gu et al., "Feasibility study on posterior laminar screw fixation techniques in the axis," Chinese Journal of Traumatology, vol. 13, no. 2, pp. 77-82, 2010.

[15] M. I. Yusof and S. S. M. Shamsi, "Translaminar screw Wxation of the cervical spine in Asian population: Feasibility and safety consideration based on computerized tomographic measurements," Surgical and Radiologic Anatomy, vol. 34, no. 3, pp. 203207, 2012.

[16] R. M. Sharma, N. Pruthi, P. Pandey, R. Dawn, Y. Ravindranath, and R. Ravindranath, "Morphometric and radiological assessments of dimensions of Axis in dry vertebrae: A study in Indian population," Indian Journal of Orthopaedics, vol. 49, no. 6, pp. 583-588, 2015.

[17] K. Saetia and A. Phankhongsab, " $\mathrm{C} 2$ anatomy for translaminar screw placement based on computerized tomographic measurements," Asian Spine Journal, vol. 9, no. 2, pp. 205-209, 2015.

[18] R. Bhatnagar, W. D. Yu, P. F. Bergin, L. E. Matteini, and J. R. O'Brien, “The anatomic suitability of the C2 vertebra for intralaminar and pedicular fixation: a computed tomography study," Spine Journal, vol. 10, no. 10, pp. 896-899, 2010. 
[19] M. Y. Wang, "Cervical crossing laminar screws: Early clinical results and complications," Neurosurgery, vol. 61, no. 5, pp. ONS311-ONS315, 2007.

[20] S. L. Parker, M. J. McGirt, G. L. Garcés-Ambrossi et al., “Translaminar versus pedicle screw fixation of C2: Comparison of surgical morbidity and accuracy of 313 consecutive screws," Neurosurgery, vol. 64, no. 5, pp. ons343-ons348, 2009.

[21] I. G. Dorward and N. M. Wright, "Seven years of experience with C2 translaminar screw fixation: Clinical series and review of the literature," Neurosurgery, vol. 68, no. 6, pp. 1491-1499, 2011.

[22] S.-A. Park, D.-S. Kwak, and S.-L. You, "Entry zone of iliac screw fixation to maintain proper entry width and screw length," European Spine Journal, vol. 24, no. 11, pp. 2573-2579, 2015.

[23] H.-J. Cho, D.-S. Kwak, and I.-B. Kim, "Morphometric evaluation of Korean femurs by geometric computation: comparisons of the sex and the population," BioMed Research International, vol. 2015, Article ID 730538, 9 pages, 2015.

[24] D.-I. Kim, D.-S. Kwak, and S.-H. Han, "Sex determination using discriminant analysis of the medial and lateral condyles of the femur in Koreans," Forensic Science International, vol. 233, no. 1-3, pp. 121-125, 2013.

[25] H. Cho, S. Kim, and D. Kwak, "Morphological study of the anterior surface of the distal radius," BioMed Research International, vol. 2017, Article ID 8963768, 5 pages, 2017.

[26] C. L. Dean, M. J. Lee, M. Robbin, and E. H. Cassinelli, "Correlation between computed tomography measurements and direct anatomic measurements of the axis for consideration of C2 laminar screw placement," Spine Journal, vol. 9, no. 3, pp. 258-262, 2009.

[27] B. Yue, D.-S. Kwak, M.-K. Kim, S.-O. Kwon, and S.-H. Han, "Morphometric trajectory analysis for the C2 crossing laminar screw technique," European Spine Journal, vol. 19, no. 5, pp. 828832,2010 

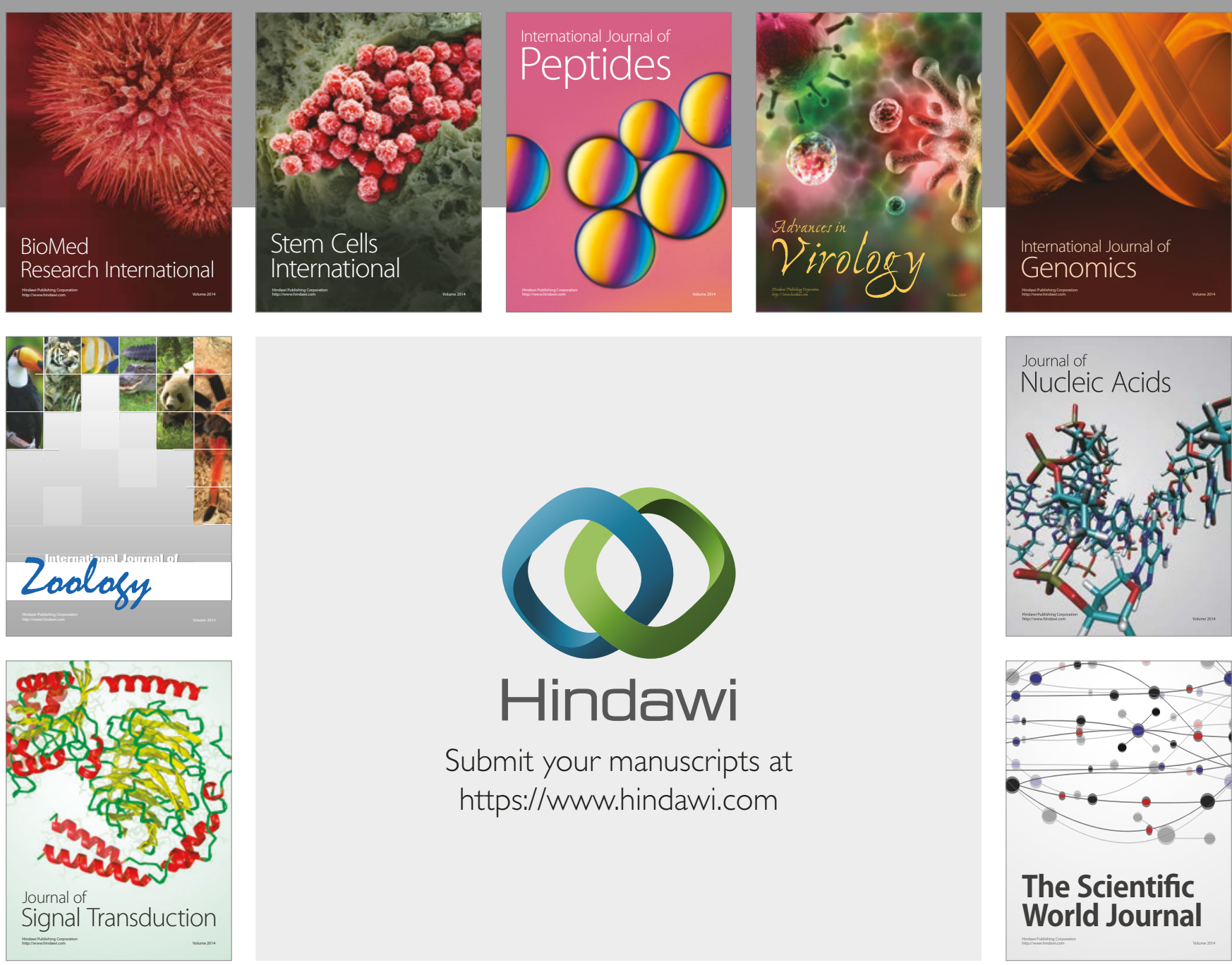

Submit your manuscripts at

https://www.hindawi.com
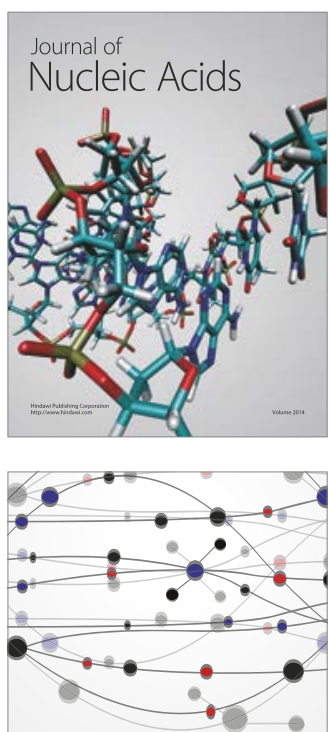

The Scientific World Journal

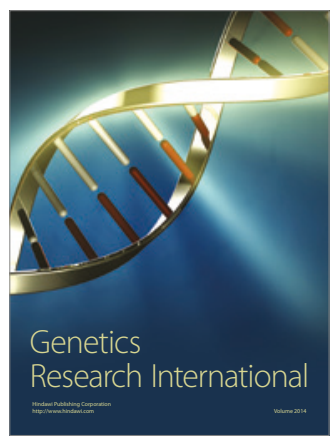

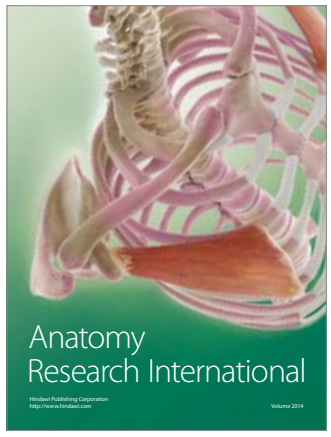

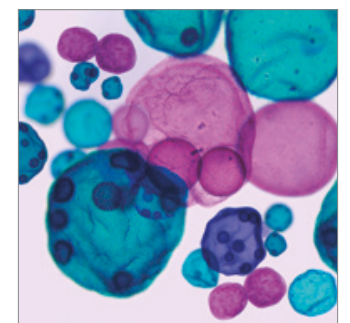

International Journal of Microbiology
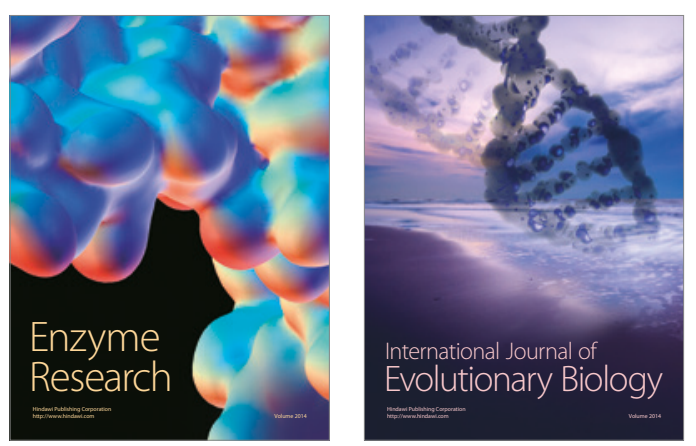
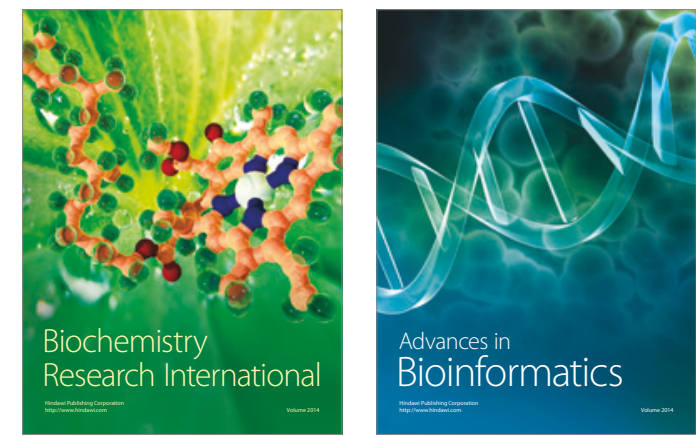

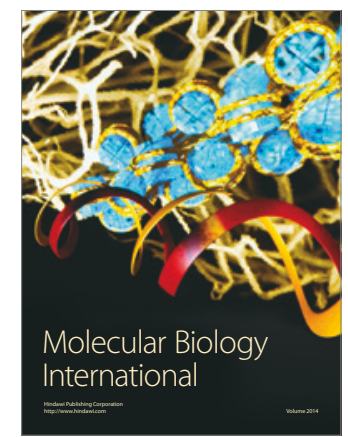

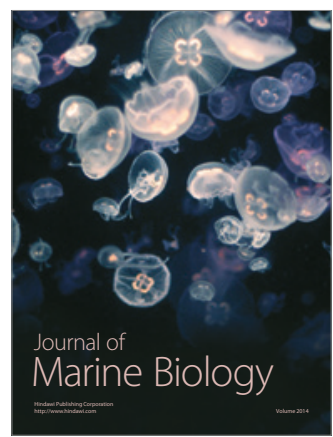

